VK. Carcinoma of the gallbladder presenting as scalp tumour. Eur J Surg Oncol. 1998;24:605-7.

8. Bartella L, Kaye J, Perry NM, Malhotra A, Evans D, Ryan D, et al. Metastases to the breast revisited: radiologicalhistopathological correlation. Clin Radiol. 2003;58:524-31.

9. Beaver BL, Denning DA, Minton JP. Metastatic breast carcinoma of the gallbladder. J Surg Oncol. 1986;31:240-2.

10. Shah RJ, Koehler A, Long JD. Bile peritonitis secondary to breast cancer metastatic to the gallbladder. Am J Gastroenterol. 2000;95:1379-81.

11. Shukla PJ, Barreto SG, Shrikhande SV, Mohandas KM, Purandare $\mathrm{N}$, Rangarajan V. Detection of gall bladder cancer metastases in rare sites by PET scan. Indian J Gastroenterol. 2007;26:303-4.

12. Garg PK, Khurana N, Hadke NS. Subcutaneous and breast metastasis from asymptomatic gallbladder carcinoma. Hepatobiliary Pancreat Dis Int. 2009; 8:209-11.

13. Singh S, Gupta P, Khanna R, Khanna AK. Simultaneous breast and ovarian metastasis from gallbladder carcinoma. Hepatobiliary Pancreat Dis Int. 2010; 9:553-4.

14. Kayikçioglu F, Boran N, Ayhan A, Güler N. Inflammatory breast metastases of ovarian cancer: a case report. Gynecol Oncol. 2001;83:613-6.

15. Moore D, Wilson DK, Hurteau J, Look KY, Stehman FB, Sutton GP. Gynecologic cancers metastatic to the breast. J Am Coll Surg. 1998;187:178-81.

16. Ricardo AE, Feig BW, Ellis LM, Hunt KK, Curley SA, MacFadyen BV, et al. Gallbladder cancer and trocar site recurrences. Am J Surg. 1997;174:619-22; discussion 6232-3.

\section{Adenoendocrinecarcinoma of gallbladder in a patient with primary sclerosing cholangitis and ulcerative colitis}

\section{Introduction}

It is well known that patients suffering from primary sclerosing cholangitis (PSC) and ulcerative colitis (UC) are at high risk for cholangiocarcinoma. In addition, ithas also been reported that the prevalence of gallbladder carcinomas is around $14 \%$ in PSC and UC patients. ${ }^{1}$ Earlier reports draw correlations not only between patients of PSC and UC with cholangiocarcinoma but also with carcinoma of the gallbladder. ${ }^{1-3}$ Regular follow-up of these patients for suspicious gallbladder lesions is thus pertinent. ${ }^{4}$

Adenoendocrinecarcinoma of gallbladder is a rare histological type. Prognostic importance of this subtype is yet to be evaluated. The adenocarcinomatous and neuroendocrine components often exist in varying proportions in this malignancy and can vary from well differentiated to poorly differentiated histopathology. In this report, we present the clinicopathological features of an adenoendocrine carcinoma of the gallbladder associated with PSC and UC. To the best of our knowledge this is the first report in literature of an adenoendocrine carcinoma of the gallbladder associated with PSC and UC.

\section{Case report}

A 48-year-old female was diagnosed with UC (pancolitis) 20 years back. She had been treated with steroids and azathioprine and the disease was in resolving phase. Later she had developed PSC with features of chronic liver disease and portal hypertension since last 7 years. Four months back she was found to have a mass lesion in the gallbladder fossa. Her liver function tests, CA19.9 and CEA were normal. CECT abdomen was performed and showed uniform mural enhancement of biliary ductal system, heterogenous ill-defined soft tissue enhancement along the gallbladder fossa and features of secondary biliary cirrhosis. MR Imaging showed a contracted gallbladder with a small non-enhancing focal area of altered signal intensity possibly indicating a small cyst. Subsequently she was subjected to endoscopic ultrasound guided FNA. Endoscopic ultrasound demonstrated a localized complex gallbladder mass lesion and thick walled bile duct. EUS guided FNA was done and the on-site cytopathology report revealed a neuroendocrine carcinoma with xanthgranulomatous inflammation, which was subsequently confirmed on examination of all the aspiration smears. PET-CT was done to detect the status of lesion which showed FDG avid heterogeneously enhancing mass in the gallbladder fossa with contiguous infiltration of adjacent IVB and V segments of the liver with an absence of FDG avid regional lymphadenopathy or distant metastatic disease (Figure 1).

Extended cholecystectomy with segmentectomy was performed and the specimen was sent for histopathology examination. Gross examination showed a contracted gallbladder adherent to the liver. Its lumen was obscured by a grey white mural thickening of the fundus, body and neck region and a focal cyst like area was noticed in the fundus area which was pushing into the liver. The growth was well marginated to the liver parenchyma. The liver parenchyma and liver resection margins were grossly free of the tumor. Microscopically neck, 


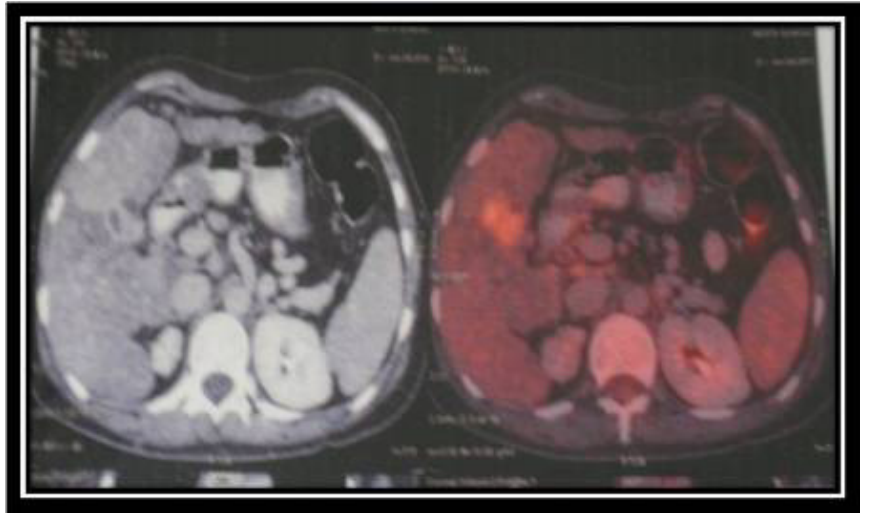

Figure 1: PET-CT suggestive of gallbladder cancer with no evidence of distant metastasis.

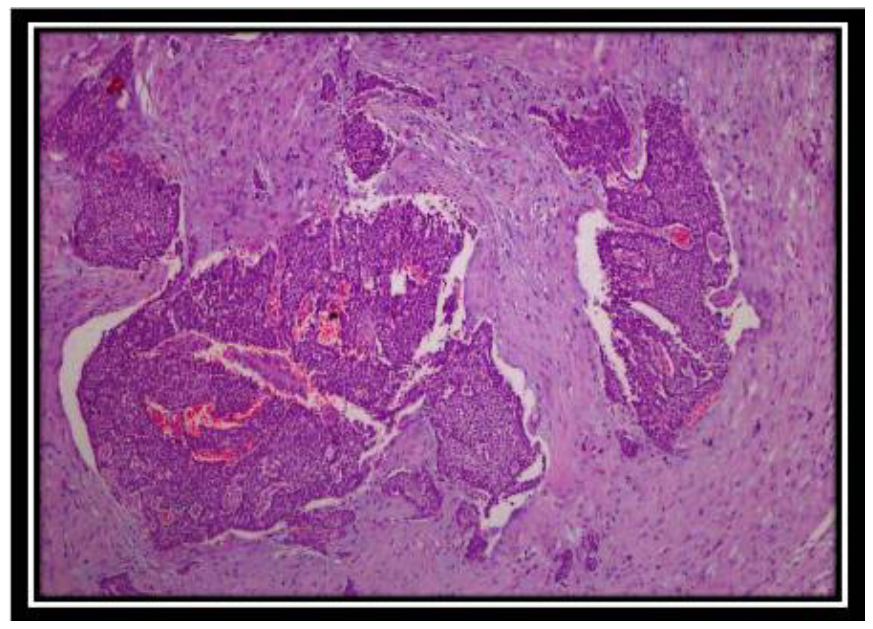

Figure 2: H\&E stained section in 200X showing neuroendocrine differentiation.

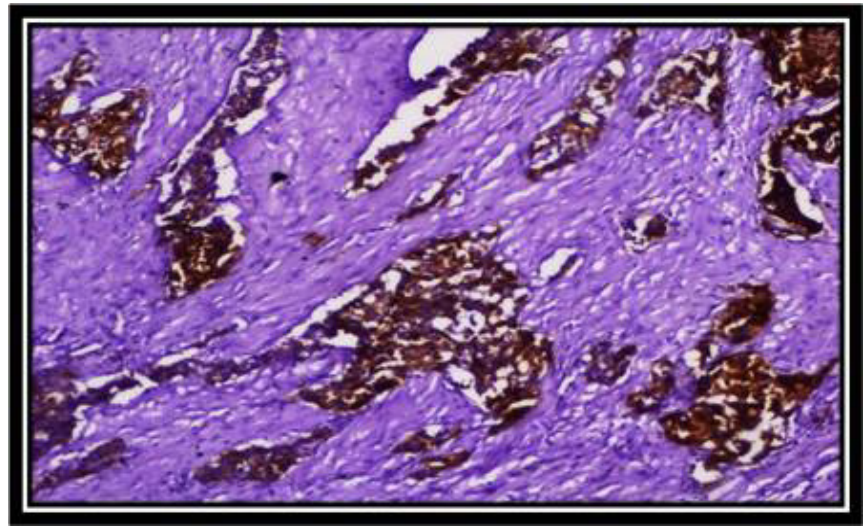

Figure 3: Neuroendocrine areas are Chromogranin A positive (200X).

body and fundus of gallbladder showed infiltration of all the wall layers by irregular malignant glands reaching upto the subserosa.There was no extension of the malignancy beyond the serosa or into the liver parenchyma. There was prominent desmoplastic reaction, areas of chronic inflammatory cells and cystic glands lined by tumor cells. Several areas with neuroendocrine differentiation were also seen (Figure 2). Few areas showed an intricate admixture of malignant columnar cells and neuroendocrine cells.Perineural, intraneural andperivascular tumor infiltration was also seen. Foci of xanthogranulomatous inflammation, pyloric and intestinal metaplasia were noted. The liver parenchyma showed features of stage 3 primary sclerosing cholangitis.Immunohistochemical studies revealed PanCytokeratin immunostaining in malignant glands and Chromogranin A and Synaptophysin staining in the trabeculae and islands of atypical cells (Figure 3).

\section{Discussion}

Primary sclerosing cholangitis (PSC) increases the risk of hepatobiliary malignancy, especially cholangiocarcinoma (CC) by 10 to $20 \%$. Carcinoma of the gallbladder have been described in PSC but are less common than bile duct carcinomas. ${ }^{1}$ But gallbladder epithelial dysplasia or malignancies can develop over a similar sequence of dysplasia-carcinoma as observed in ulcerative colitis. ${ }^{2}$ Lewis et al evaluated 72 gallbladders from liver explants with PSC.They noted pyloric metaplasia in $96 \%$, intestinal metaplasia in 50\%,dysplasia in $37 \%$ and adenocarcinoma in $14 \%$ cases. Gallbladder inflammatory or malignant lesions that occur in PSC can initially be diagnosed by radiology. Early diagnosis is critical for patient survival and successful outcome.Review of literature indicates that PSC and UC patients are not only at high risk for cholangiocarcinoma but also for gallbladder carcinoma. So these patients require regular follow-up and repeat radiological examinations even if the disease is under control. ${ }^{3,4}$

The common carcinoma ofthe gallbladder is adenocarcinoma but few rare cases of adenoendocrine carcinoma have been reported. ${ }^{5,6}$ Other rare types such as undifferentiated carcinoma and signet ring cell carcinoma, squamous cell admixed with neuroendocrine differentiation, large cell neuroendocrine carcinoma with adenocarcinoma andmucin producing carcinoma have also been reported. ${ }^{7-}$ ${ }^{11}$ Coexistence of adenocarcinoma and neuroendocrine cell carcinoma is even rarer. The carcinomatous component is either an ordinary adenocarcinoma, undifferentiated carcinoma or signet ring carcinoma. ${ }^{8,9}$ The neuroendocrine component on the other hand is generally nonfunctional and comprises about $1 / 3$ of the total tumor mass. ${ }^{12}$ Two hypotheses have been proposed for the histogenesis of the neuroendocrine component. One hypothesis proposes coincidental neoplastic changes in two different cell types, ${ }^{13}$ while the second hypothesis proposes neoplastic change in a single common precursor pluripotent cancer stem cell which differentiates into 
different cell lineages. ${ }^{7}$ While the first hypothesis is controversial, the second is considered more compatible with the observed pathology in these tumors. Noteworthy is the presence of transition zones between the carcinomatous and neuroendocrine components, thus interweaving an intricate admixture of different cell types.It has been suggested that the histogenesis of endocrine cell carcinoma of the gallbladder is closely related to that of adenocarcinoma.Since there are very few reports on mixed gallbladder tumors, the clinical importance of morphological subtyping of this tumorhas not been yet established. Carcinomas of the extrahepatic biliary tract with pure or predominant exocrine differentiation have better prognosis as compared to carcinomas with neuroendocrine differentiation, the latter being associated with shorter survival time. ${ }^{14}$ The current case is being thus reported for its rarity in association of adenoendocrine carcinoma with primary sclerosingcholangitis and ulcerative colitis.

\section{ARCHANA RASTOGI ${ }^{1}$ CHHAGAN BIHARI ${ }^{1}$ SHIVENDER SINGH ${ }^{2}$ PRANJAL DEKA ${ }^{2}$ VIKRAM BHATIA ${ }^{3}$ SHIV SARIN ${ }^{3}$ \\ Correspondence: Dr. ArchanaRastogi Departments of Pathology, ${ }^{1}$ Hepato-Pancreato-Biliary Surgery, ${ }^{2}$ and Hepatology, ${ }^{3}$ Institute of Liver and Biliary sciences (ILBS), \\ New Delhi, India \\ Email: drarchanarastogi@gmail.com}

\section{References}

1. Lewis JT, Talwalkar JA, Rosen CB, Smyrk TC, Abraham SC. Prevalence and risk factors for gallbladder neoplasia in patients with primary sclerosing cholangitis: evidence for a metaplasiadysplasia-carcinoma sequen. Am J SurgPathol. 2007;31:907-13.

2. Buckles DC, Lindor KD, Larusso NF, Petrovic LM, Gores GJ. In primary sclerosing cholangitis, gallbladder polyps are frequently malignant.Am J Gastroenterol. 2002;97:1138-42.

3. Brandt DJ, MacCarty RL, Charboneau JW, LaRusso NF, Wiesner $\mathrm{RH}$, Ludwig J. Gallbladder disease in patients with primary sclerosing cholangitis.AJR Am J Roentgenol.1988;150:571-4.

4. Yamamoto T, Uki K, Takeuchi K, Nagashima N, Honjo H, Sakurai $\mathrm{N}$, et al. Early gallbladder carcinoma associated with primary sclerosing cholangitis and ulcerative colitis. J Gastroenterol. 2003;38:704-6.

5. Shimizu T, Tajiri T, Akimaru K, Arima Y, Yoshida H, Yokomuro $\mathrm{S}$, et al.Combined neuroendocrine cell carcinoma and adenocarcinoma of the gallbladder: report of a case. J Nihon Med Sch. 2006;73:101-5.
6. Tsuchiya A, Endo Y, Yazawa T, Saito A, Inoue N. Adenoendocrine cell carcinoma of the gallbladder: report of a case. Surg Today.2006;36:849-52.

7. Sato K, Imai T, Shirota Y, Ueda Y, Katsuda S.Combined large cell neuroendocrine carcinoma and adenocarcinoma of the gallbladder. Pathol Res Pract. 2010;206:397-400.

8. Ito J, Mishushima M, Soto H. Composite tumour exhibiting both carcinoid and undifferentiated carcinoma of gall bladder. $\mathrm{Tr}$ Soc Pathol Jpn. 1980;69:3699.

9. Olinici CD, Waslu R. Composite endocrine cell, typical adeno carcinoma and signet cell carcinoma of the gall bladder. Rom J Morphol Embryol. 1991;110:604-10.

10. Noda H, Chiba F, Toyama N, Konishi F. Mucin-producing carcinoma of the gallbladder associatedwith primary sclerosing cholangitis and ulcerative colitis. J Hepatobiliary Pancreat Surg. 2009;16:83-5.

11. Iida Y, Tsutsumi Y. Small cell (endocrine cell) carcinoma of the gallbladder with squamous and adenocarcinomatous components. Acta Pathol Jpn. 1992;42:119-25.

12. Iype S, Mirza TA, Propper DJ, Bhattacharya S, Feakins RM, Kocher HM. Neuroendocrine tumours of the gallbladder: three cases and a review of the literature.Postgrad Med J. 2009;85:213-8.

13. Wisniewski M, Toker C. Composite tumours of the gall bladder exhibiting both carcinomatous and carcinoid pattern. Am J Gastroenterol. 1972;58:633-7.

14. Hsu W, Deziel DJ, Gould VE, Warren WH, Gooch GT, Staren ED.Neuroendocrine differentiation and prognosis ofextra hepatic biliary tract carcinomas. Surgery. 1991;110:604-10; discussion 610-1.

\section{Revision shunt for Budd-Chiari syndrome}

\section{Introduction}

Budd-Chiarisyndrome(BCS) results from an obstruction to the hepatic venous outflow and may occur at any level starting from the small hepatic veins(HV) to the cavo-atrial junction. ${ }^{1}$ Various treatment modalities have been proposed for the management of this condition. In a significant proportion of these patients, surgical decompressive procedures (shunt operations)are effective in decongesting the liver and improving the survival before the onset of cirrhosis. ${ }^{2}$ Mesoatrial shunt has been used for the management of patients with BCS due to combined hepatic venous and inferior vena cava (IVC) obstruction, not amenable to caval stenting. The procedure was first described in 1978 by Cameron et al in a patient of BCS with inferior vena cava obstruction to divert the portal blood 